\title{
Faktor-Faktor yang Berhubungan dengan Pelaksanaan Penerapan Standar Asuhan Persalinan Normal Oleh Bidan Puskesmas Rawat Inap di Kabupaten Bungo Provinsi Jambi
}

\author{
Evrina Solvia Soleh ${ }^{1}$, Masrul $^{2}$, Desmiwarti ${ }^{3}$ \\ Pascasarjana Ilmu Kebidanan Fakultas Kedokteran Universitas Andalas, Padang \\ Ilmu Gizi, Fakultas Kedokteran Univesitas Andalas, Padang ${ }^{2}$ \\ Obstetri Gynecologi, Fakultas Kedokteran, Universitas Andalas, Padang ${ }^{3}$ \\ Email : rina3288@gmail.com /085263613584
}

\begin{abstract}
Implementation of Standard Normal Birth Assembly is an integrated effort in reducing MMR and IMR. This activity is very important to be carried out considering that Bungo Regency has the highest maternal and infant mortality rates in Jambi Province. Several factors related to Standard Application of Normal Birth care in Bungo Regency are: Education, Training, Motivation, Perceptions of Rewards, Experience and Facilities. The objective of this research is to know factors related to the implementation of Normal Birth Standard by Inpatient Health Center Midwife in Bungo Regency. This study is an analytic observational study with a cross-sectional design of 47 midwives who served in Bungo Regency inpatient Health Center from July to September 2017. Respondents were interviewed and observed in implementing normal labor standards. Data processing was done by computerization and analyzed statistically using univariate, bivariate, and multivariate analysis with product moment correlation. There is a relationship between training with the implementation of normal labor standards $(p=0.001)$, there is a relationship between experience with the implementation of normal labor standards $(p=0.010)$. There is no correlation between perceptions of rewards and the implementation of normal labor $(p=0.539)$, there is no educational relationship with the implementation of normal labor standards $(p=0.404)$ and motivation with the implementation of normal labor standards $(p=1,000)$. The conclusion of this study is that training is the dominant factor that relates to the implementation of normal labor standards by midwives at the health center in Bungo regency.
\end{abstract}

Key words: APN Standards, Education, Training, Motivation, Perceptions of Rewards, and Experience

\section{PENDAHULUAN}

Jumlah kematian ibu di Provinsi Jambi tahun 2014 terbanyak terdapat di Kota Jambi yaitu (9 kasus), Kabupaten Merangin (8kasus)dan Kabupaten Bungo berada diposisi ketiga tertinggi yaitu (5kasus) (Dinkes Jambi, 2015)

Pada tahun 2015 kematian Ibu di Kabupaten Bungo Meningkat drastis yaitu 46 kasus dan sampai bulan Juli tahun 2016 kematian Ibu sudah mencapai 18 kasus. Saat ini Kabupaten Bungo berada diposisi pertama tertinggi kematian ibu ( Dinkes Bungo, 2016).

Persalinan yang aman memang sangat dibutuhkan karena persalinan merupakan proses yang normal serta suatu kejadian yang sehat. Akan tetapi potensi komplikasi yang mengancam nyawa juga akan selalu ada, sehingga bidan harus mengamati dengan ketat ibu dan bayinya sepanjang kelahiran. Selain itu, semua penolong persalinan harus mempunyai bekal pengetahuan, ketrampilan, dan alat untuk memberikan pertolongan yang aman dan bersih, serta memperhatikan lingkungan sekitar (Sarwono, 2002).

Dalam hal ini, pertolongan persalinan yang menggunakan prinsip asuhan persalinan normal tersebut dapat menekan angka kematian ibu 40-45 per 100.000 kelahiran hidup (Koagouw, 2007).

Berdasarkan hasil pengamatan yang penulis lakukan pada bulan Januari 2016 yaitu melalui pengamatan pada dokumentasi dalam partograf. Dari 12 orang bidan di Puskesmas Rawat Inap Kabupaten Bungo baru 4 orang $(33,33 \%)$ bidan yang melaksanakan pelayanan persalinan dengan Standar Asuhan Persalinan Normal, sedangkan sebanyak 8 orang bidan $(66,67 \%)$ belum melaksanakan pelayanan persalinan sesuai dengan Standar Asuhan Persalinan Normal yang ada. Terutama pada penggunaan Partograf, Bidan mengisi partograf 
pada grafik pembukaan servik dan grafik Denyut Jantung Janin ( DJJ ) setelah pertolongan persalinan selesai. Semestinya partograf diisi setiap selesai evaluasi untuk memantau kemajuan persalinan dan kesejahteraan janin didalam uterus.

Bidan merupakan tenaga lini terdepan harus mampu dan terampil dalam memberikan pelayanan kebidanan kepada ibu dan bayi baru lahir sesuai dengan asuhan kebidanan yang ditetapkan, mengacu kepada kewenangan dan kode etik profesi serta ditunjang dengan sarana dan prasarana yang terstandar. Untuk mendukung peningkatan keterampilan bidan dalam memberikan pelayanan yang berkualitas, Depkes telah menyusun berbagai pedoman dan standar asuhan kebidanan sehingga dapat digunakan sebagai acuan. Seiring dengan itu pula pemerintah dan berbagai pihak di Indonesia terus mengembangkan pendidikan kebidanan yang berhubungan dengan perkembangan pelayanan kebidanan baik pendidikan formal maupun non formal.

Berdasarkan hasil wawancara dengan 12 orang bidan, sebagian besar bidan menyatakan bahwa belum pernah mengikuti pelatihan APN dengan alasan keterbatasan biaya, waktu dan tempat. Untuk mengikuti pelatihan APN yang biayanya cukup mahal bidan harus membayar dengan uang pribadi tanpa ada bantuan dari instansi terkait (Pihak Puskesmas).Selain itu keterbatasan waktu untuk mengikuti pelatihan yang cukup lama dan lokasi pelatihan berada jauh dari Kabupaten Bungo, yaitu di Kota jambi juga menjadi alasan para Bidan enggan mengikuti pelatihan APN.

Berdasarkan hasil investigasi kualitas cepat (Quick Investigation of Quality) yang dilakukan pada bulan juli 1997 di provinsi Jawa Tengah dan Jawa Timur, terungkap bahwa hampir sebagian besar (80\%) penolong persalinan yang bekerja di fasilitas kesehatan, tidak mampu melakukan asuhan persalinan sesuai dengan standar yang diinginkan. Tidak tersedianya standar asuhan, terbatasnya pengetahuan dan keterampilan yang dibutuhkan, dan kurangnya kepatuhan petugas terhadap standar menyebabkan rendahnya kinerja dan kualitas pelayanan. Hal tersebut di atas, juga merupakan bahan kajian kebutuhan pelatihan petugas kesehatan sebagai pelaksana asuhan persalinan, terutama bagi mereka yang bekerja di lini terdepan atau pedesaan ( JNKPKK-KR, 2012).
Fakta dilapangan bahwa tingginya AKI di Kabupaten Bungo memperlihatkan kinerjabidan dalam pelaksanaan upaya tersebut masih belum memenuhi harapan. Seharusnya kompetensi bidan dalam pertolongan persalinan sesuai APN dapat menekan AKI. Sarana yang telah memadai serta akses pelayanan kesehatan yang telah menjangkau seluruh pelosok wilayah Kabupaten Bungo, tapi belum mampu menurunkan AKI secara signifikan.

Berdasarkan latar belakang yang telah penulis uraikan dan berdasarkan hasil penelitian terdahulu, maka penulis tertarik untuk melakukan penelitian kembali tentang: "Faktorfaktor yang berhubungan dengan Pelaksanaan Penerapan Standar Asuhan Persalinan Normal (APN) oleh bidan Puskesmas Rawat Inap di Kabupaten Bungo".

Mengetahui faktor-faktor yang berhubungan dengan pelaksanaan penerapan Standar Asuhan Persalinan Normal (APN) oleh bidan Puskesmas Rawat Inap di Kabupaten Bungo.

\section{METODE PENELITIAN}

Penelitian ini merupakan penelitian kuantitatif. Jenis penelitian yang dilakukan adalah observasional dengan desain Cross sectional Study. Populasi dalam penelitian ini adalah Seluruh bidan yang bertugas di Puskesmas Rawat Inap Kabupaten Bungo sejumlah 73 orang bidan. Sampel penelitian ini adalah bidan yang bertugas pada puskesmas rawat inap di Kabupaten Bungo yang memenuhi kriteria inklusi dan ekslusi.

\section{HASIL DAN PEMBAHASAN}

Penelitian ini dilakukan di Puskesmas Rawat Inap Kabupaten Bungo pada bulan Juli hingga September 2017. Responden dalam penelitian ini sebanyak 47 Bidan yang bertugas di Puskesmas Rawat inap di Kabupaten Bungo.

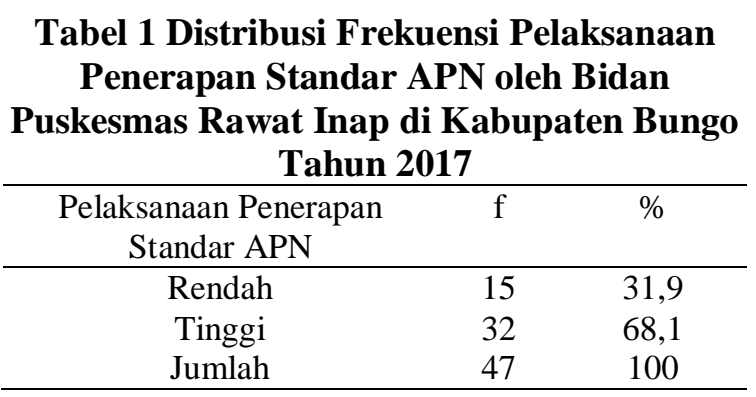

Berdasarkan tabel 1 diketahui bahwa lebih dari setengah pelaksanaan penerapan standar 
APN oleh Bidan Puskesmas Rawat Inap di Kabupaten Bungo Tahun 2017 dalam kategori tinggi $(68,1 \%)$.

\section{Tabel 2 Distribusi Frekuensi Tingkat} Pendidikan Bidan Puskesmas Rawat Inap di Kabupaten Bungo Tahun 2017

\begin{tabular}{ccc}
\hline Pendidikan & $\mathrm{f}$ & $\%$ \\
\hline Rendah & 7 & 14,9 \\
Tinggi & 40 & 85,1 \\
Jumlah & 47 & 100 \\
\hline
\end{tabular}

Pada tabel 2 diketahui bahwa sebagian kecil responden dengan tingkat pendidikan rendah $(14,9 \%)$.

Tabel 3 Distribusi Frekuensi Pelatihan Bidan Puskesmas Rawat Inap

di Kabupaten Bungo Tahun 2017

\begin{tabular}{ccc}
\hline Pelatihan & f & $\%$ \\
\hline Tidak Pernah & 28 & 59,6 \\
pernah & 19 & 40,4 \\
Jumlah & 47 & 100 \\
\hline
\end{tabular}

Pada tabel 3 diketahui bahwa lebih dari setengah responden tidak pernah mengikuti pelatihan APN $(59,6 \%)$.

Tabel 4 Distribusi Frekuensi Motivasi Bidan Puskesmas Rawat Inap

di Kabupaten Bungo Tahun 2017

\begin{tabular}{ccc}
\hline Motivasi & $\mathrm{f}$ & $\%$ \\
\hline Rendah & 11 & 23,4 \\
Tinggi & 36 & 76,6 \\
Jumlah & 47 & 100 \\
\hline
\end{tabular}

Pada tabel 4 diketahui bahwa sebagian besar responden memiliki motivasi tinggi $(76,6 \%)$.
Tabel 5. Distribusi Frekuensi Persepsi terhadap imbalan Bidan Puskesmas Rawat

Inap di Kabupaten Bungo Tahun 2017

\begin{tabular}{ccc}
\hline Persepsi terhadap Imbalan & f & $\%$ \\
\hline Tidak Sesuai & 25 & 53,2 \\
Sesuai & 22 & 46,8 \\
Jumlah & 47 & 100 \\
\hline
\end{tabular}

Pada tabel 5 diketahui bahwa lebih dari setengah responden menyatakan tidak sesuai dalam pemberian imbalan sebanyak $(53,2 \%)$.

Tabel 6 Distribusi Frekuensi Pengalaman Bidan Puskesmas Rawat Inap

di Kabupaten Bungo Tahun 2017

\begin{tabular}{ccc}
\hline Pengalaman & f & $\%$ \\
\hline Kurang & 28 & 59,6 \\
Baik & 19 & 40,4 \\
Jumlah & 47 & 100 \\
\hline
\end{tabular}

Pada tabel 6 diketahui bahwa lebih dari setengah responden memiliki pengalaman kurang $(59,6 \%)$.

Tabel 7 Distribusi Frekuensi Pengalaman

Bidan Puskesmas Rawat Inap

di Kabupaten Bungo Tahun 2017

\begin{tabular}{lccc}
\hline \multicolumn{2}{c}{ Sarana } & f & $\%$ \\
\hline $\begin{array}{l}\text { Tidak Sesuai dengan standar } \\
\text { minimal }\end{array}$ & 4 & 67 \\
sesuai dengan standar minimal & 2 & 33 \\
\multicolumn{2}{c}{ Jumlah } & 6 & 100 \\
\hline
\end{tabular}

Pada tabel 7 diketahui bahwa lebih dari setengah puskesmas rawat inap memiliki sarana pertolongan persalinan yang tidak sesuai dengan standar minimal $(67 \%)$.

Tabel 8 Hubungan Tingkat Pendidikan dengan Pelaksanaan Standar APN oleh Bidan di Puskesmas Rawat Inap Kabupaten Bungo Tahun 2017

\begin{tabular}{lccccccc}
\hline \multicolumn{1}{c}{$\begin{array}{c}\text { Tingkat } \\
\text { Pendidikan }\end{array}$} & \multicolumn{2}{c}{ Pelaksanaan Standar APN } & \multicolumn{3}{c}{ Total } & \multirow{2}{*}{ Nilai p } \\
\hline Rendah & $\mathrm{f}$ & $\%$ & $\mathrm{f}$ & $\%$ & $\mathrm{f}$ & $\%$ & \\
Tinggi & 1 & 14,3 & 6 & 85,7 & 7 & 100 & \\
Total & 14 & 35,0 & 26 & 65,0 & 40 & 100 & 0,404 \\
\hline
\end{tabular}

Berdasarkan tabel 8 diperoleh nilai $\mathrm{p}>0,05$ maka dapat disimpulkan tidak ada hubungan yang signifikan antara tingkat pendidikan dengan pelaksanaan standar APN. 
Tabel 9 Hubungan Pelatihan dengan Pelaksanaan Standar APN oleh Bidan di Puskesmas Rawat Inap Kabupaten Bungo Tahun 2017

\begin{tabular}{lrrrrrrrr}
\hline & \multicolumn{3}{c}{ Pelaksanaan Standar APN } & \multicolumn{2}{c}{ Total } & \multirow{2}{*}{ Nilai p } \\
\multicolumn{1}{c}{ APN } & Rendah & f & $\%$ & f & $\%$ & f & $\%$ & \\
\hline Tidak Pernah & 14 & 50 & 14 & 50 & 28 & 100 & \\
Pernah & 1 & 5,3 & 18 & 94,7 & 19 & 100 & 0,001 \\
Total & 15 & 31,9 & 32 & 68,1 & 47 & 100 & \\
\hline
\end{tabular}

Berdasarkan tabel 9 diperoleh nilai $\mathrm{p}<$ yang signifikan antara pelatihan APN dengan 0,05 maka dapat disimpulkan ada hubungan pelaksanaan standar APN.

Tabel 10 Hubungan Tingkat Motivasi dengan Pelaksanaan Standar APN oleh Bidan di Puskesmas Rawat Inap Kabupaten Bungo Tahun 2017

\begin{tabular}{|c|c|c|c|c|c|c|c|}
\hline \multirow{3}{*}{$\begin{array}{l}\text { Tingkat } \\
\text { Motivasi }\end{array}$} & \multicolumn{4}{|c|}{ Pelaksanaan Standar APN } & \multicolumn{2}{|c|}{ Total } & \multirow[t]{3}{*}{ Nilai p } \\
\hline & \multicolumn{2}{|c|}{ Rendah } & \multicolumn{2}{|c|}{ Tinggi } & & & \\
\hline & $f$ & $\%$ & $f$ & $\%$ & $\mathrm{f}$ & $\%$ & \\
\hline Rendah & 3 & 27,3 & 8 & 72,7 & 11 & 100 & \\
\hline Tinggi & 12 & 33,3 & 24 & 66,7 & 36 & 100 & 1,000 \\
\hline Total & 15 & 31,9 & 32 & 68,1 & 47 & 100 & \\
\hline
\end{tabular}

Berdasarkan tabel 10 dapat disimpulkan tidak ada hubungan yang signifikan antara tingkat motivasi dengan pelaksanaan standar APN.

Tabel 11 Hubungan Persepsi Terhadap Imbalan dengan Pelaksanaan Standar APN oleh Bidan di Puskesmas Rawat Inap Kabupaten Bungo Tahun 2017

\begin{tabular}{|c|c|c|c|c|c|c|c|}
\hline \multirow{3}{*}{$\begin{array}{l}\text { Persepsi } \\
\text { Imbalan }\end{array}$} & \multicolumn{4}{|c|}{ Pelaksanaan Standar APN } & \multicolumn{2}{|c|}{ Total } & \multirow[t]{3}{*}{ Nilai $p$} \\
\hline & \multicolumn{2}{|c|}{ Rendah } & \multicolumn{2}{|c|}{ Tinggi } & & & \\
\hline & $\mathrm{f}$ & $\%$ & $\mathrm{f}$ & $\%$ & $\mathrm{f}$ & $\%$ & \\
\hline Tidak Sesuai & 7 & 28 & 18 & 72 & 25 & 100 & \\
\hline Sesuai & 8 & 36,4 & 14 & 63,6 & 22 & 100 & 0,539 \\
\hline Total & 15 & 31,9 & 32 & 68,1 & 47 & 100 & \\
\hline
\end{tabular}

Berdasarkan tabel 11 diperoleh nilai $\mathrm{p}>$ 0,05 maka dapat disimpulkan tidak ada hubungan yang signifikan antara persepsi

Tabel 12. Hubungan Pengalaman dengan Pelaksanaan Standar APN oleh Bidan di Puskesmas Rawat Inap Kabupaten Bungo Tahun 2017

\begin{tabular}{|c|c|c|c|c|c|c|c|}
\hline \multirow{3}{*}{ Pengalaman } & \multicolumn{4}{|c|}{ Pelaksanaan Standar APN } & \multicolumn{2}{|c|}{ Total } & \multirow[t]{3}{*}{ Nilai $p$} \\
\hline & \multicolumn{2}{|c|}{ Rendah } & \multicolumn{2}{|c|}{ Tinggi } & & & \\
\hline & $\mathrm{f}$ & $\%$ & $\mathrm{f}$ & $\%$ & $\mathrm{f}$ & $\%$ & \\
\hline Kurang & 13 & 46,4 & 15 & 53,6 & 28 & 100 & \\
\hline Baik & 2 & 10,5 & 17 & 89,5 & 19 & 100 & 0,010 \\
\hline Total & 15 & 31,9 & 32 & 68,1 & 47 & 100 & \\
\hline
\end{tabular}

Berdasarkan tabel 12 diperoleh nilai $\mathrm{p}<$ 0,05 maka dapat disimpulkan terdapat hubungan yang signifikan antara pengalaman dengan pelaksanaan standar APN.

\section{Pembahasan}

Hasil penelitian membuktikan bahwa pelatihan APN merupakan faktor yang paling dominan berhubungan dengan pelaksanaan terhadap imbalan dengan pelaksanaan standar APN. standar APN, dengan nilai signifikan secara statistik sebesar 0,012 dan angka odds ratio sebesar 17,004 artinya kecendrungan responden yang pernah mengikuti pelatihan APN untuk dapat melaksanakan standar APN kategori tinggi hampir 17 kalinya jika dibandingkan dengan responden yang tidak pernah mengikuti pelatihan APN. 
Hasil penelitian ini menunjukkan bahwa keikutsertaan bidan dalam pelatihan APN akan mempengaruhi pelaksanaan standar APN. Semakin tinggi pengetahuan responden maka pelaksanaan standar APN juga semakin tinggi. Untuk meningkatkan pengetahuan responden tentang APN dapat dilakukan upaya yaitu dengan mendorong responden untuk gemar mengikuti pelatihan, seminar ataupun workshop. Pelatihan APN sebagai salah satu pendidikan nonformal, menjadi salah satu cara yang dapat diberikan kepada bidan untuk meningkatkan.pengetahuannya. Seorang penolong persalinan menurut Depkes RI (2008) harus mendapatkan kualifikasi sebagai tenaga pelaksana pertolongan persalinan melalui serangkaian pelatihan, bimbingan langsung dan kesempatan untuk mempraktekkan keterampilannya pada praktek yang sesungguhnya. Penolong persalinan harus mampu melakukan penatalaksanaan awal terhadap komplikasi persalinan, termasuk penatalaksanaan awal bila didapatkan komplikasi pada bayi baru lahir. Penolong persalinan juga harus mampu untuk melakukan rujukan ibu maupun bayi bila komplikasi yang terjadi memerlukan penatalaksanaan lebih lanjut dimana dibutuhkan keterampilan di luar kompetensi yang dimilikinya. Seorang penolong persalinan juga harus memiliki kesabaran dan kemampuan untuk berempati dimana hal ini sangat diperlukan dalam memberikan dukungan bagi ibu dan keluarganya.

\section{SIMPULAN}

Tidak ada hubungan yang signifikan antara tingkat pendidikan dengan pelaksanaan standar APN. Ada hubungan yang signifikan antara pelatihan APN dengan pelaksanaan standar APN dan Pelatihan APN merupakan faktor paling dominan yang berhubungan dengan pelaksanaan standar APN.

\section{DAFTAR PUSTAKA}

Adiputri, Ari, N.I. 2014."Hubungan Kompetensi, Kompensasi Finansial Dan Supervisi Dengan Kinerja Bidan Desa Di Kabupaten Bangli”. Tesis. Program Pascasarjana.UniversitasUdayana. Denpasar

Azwar, A. 2010.Pengantar Administrasi Kesehatan. Jakarta: Binarupa Aksara.

Dahlan, M. S. 2013. Statitiska Untuk Kedokteran dan Kesehatan.Jakarta: Salemba Medika.
Depkes RI. 2000. Standar Pelayanan Kebidanan. Jakarta: Ikatan Bidan Indonesia

Dinkes Kabupaten Bungo. 2016. Laporan Tahunan Seksi Kesehatan

Dinkes Provinsi Jambi. 2015. Profil Kesehatan Jambi 2014.

Elsi. 2016. "Analisa faktor-faktor yang berhubungan dengan kinerja Bidan Puskesmas dalam Pelayanan Antenatal di Puskesmas Kabupaten Agam tahun 2015. Tesis. Program Pascasarjana Universitas Andalas Padang. Padang."

Gitosudarmo, Indrayo, Sudito. 2000. Perilaku Keorganisasian (Edisi 1). Yogyakarta: BPFE.

Handoko, hani. T, Sukanto. R. 1996. Organisasai Perusahaan (Edisi 2).Yogyakarta: BPFE.

JNPK-KR. 2012.Pelatihan Klinik asuhan Persalinan Normal. Jakarta: Depkes RI.

Kemenkes RI. 2015. Profil Kesehatan Indonesia Tahun 2014. Jakarta: Kemenkes RI.

Leavitt, H. 1997. Managerial Psychologi Fourth Edition (Terjemahan: Muslichah Zarkasi). Jakarta: Erlangga.

Machfudloh, H, Kartasurya, M.I, Dharminto. 2014. "Faktor-Faktor yang Mempengaruhi Kinerja Bidan dalam Pelaksanaan Stimulasi Deteksi dan Intervensi Dini Tumbuh kembang Balita dan Anak Prasekolah". Jurnal Kesehatan Masyarakat Universitas Diponegoro Semarang. Semarang.

Mariati, U. Yusefni, E. Erwani. 2010. "Faktorfaktor yang Berhubungan dengan Penerapan Standar Pelayanan Kebidanan dalam Antenatal Care oleh Bidan Praktek Swasta Di Kecamatan Padang Selatan Kota Padang. Jurnal. Poltekkes Kemenkes Padang. Padang.

Notoatmodjo, S. 2010. Ilmu Perilaku Kesehatan. Jakarta: Rineka Cipta.

Nurbayak, Hamzah, A, Amir, Y. 2012."FaktorFaktor yang Berhubungan dengan Kinerja Perawat di Bagian Unit Rawat Inap Rumah Sakit Umum Daya Makassar". Jurnal. Kesehatan Masyarakat Universitas Hasanudin Makassar. Makassar.

Palutturi, S. 2008. Determinan Kinerja Bidan di Puskesmas Tahun 2006. Jurnal Manajemen Pelayanan kesehatan. Vol 11. Nomor 02. 
PP IBI. 2006. Bidan Menyongsong Masa Depan 50 Tahun IBI. Jakarta: Ikatan Bidan Indonesia.

Putri, R. Agung, I.W, Andarini, S. 2015. "Pengaruh Faktor Instrinsik dan Ekstrinsik terhadap Pelaksanaan Inisiasi menyusu Dini oleh Bidan di Puskesmas Rawat Inap". Jurnal. Kedokteran Brawijaya Malang, Vol 28 No.3 Th 2015. Malang.

Ratifah. 2006. "Analisis Faktor - Faktor yang Berhubungan Dengan Pelaksanaan Penerapan Standar Asuhan Persalinan Normal (APN) oleh Bidan Puskesmas Rawat Inap di Kabupaten Banyumas". Tesis. Program Pascasarjana.Universitas Diponegoro. Semarang.

Saifuddin, BA(ed). 2011. Buku Acuan Nasional Pelayanan Kesehatan Maternal dan Neonatal. Jakarta: Yayasan Bina Pustaka Sarwono Prawiroharjo.

Saifuddin, BA(ed). 2002. Buku Panduan Praktis Pelayanan Kesehatan Maternal dan Neonatal. Edisi I. Jakarta: Yayasan Bina Pustaka Sarwono Prawiroharjo.

Setiawan. A, Saryono. 2011. Metodologi penelitian Kebidanan DIII, DIV, SI dan S2. Yogyakarta: Nuha Medika.

Setiawan, W. 2007."Beberapa Faktor Yang Berhubungan Dengan Kinerja Bidan Di Desa Dalam Pertolongan Persalinan Di Kabupaten Tasikmalaya”.Propoosal Tesis. Program Pascasarjana. Universitas Diponegoro. Semarang.

Solita, Stanton, W.J. 1993.Prinsip Pemasaran (Edisi Ke 7 Jilid 2). Jakarta: Erlangga

Sukmasari, H. 2011. "Pengaruh kepemimpinan, motivasi, insentif, lingkungan kerja, dan kepuasan kerja terhadap kinerja pegawai dinas pengelolaan keuangan dan asset daerah kota semarang". Tesis. Program Pascasarjana.Universitas Dian Nuswantoro Semarang.

Sukmayenti. 2013. "Faktor-faktor yang berhubungan dengan pelaksanaan standar asuhan persalinan normal oleh Bidan di puskesmas rawat inap kota Padang". Tesis. Program Pascasarjana. Universitas Andalas. Padang.

Syafrudin, 2009, Organisasi Dan Manajemen Pelayanan Kesehatan Dalam Kebidanan. Jakarta: Trans info medika.

Wawan. A, Dewi. M. 2011. Teori dan pengukuran Pengetahuan Sikap dan
Perilaku Manusia. Yogyakarta: Nuha Medika

Wattimena, M. 2008. "Analisa Penerapan Standar Asuhan Persalinan Normal (APN)

Oleh Bidan Di Rumah Sakit Umum Daerah Kabupaten Sorong Papua Barat". Tesis. Program Pascasarjana. Universitas Diponegoro. Semarang.

Yosmela, R. 2017. “ Analisa Hubungan Budaya Organisasi Rumah sakit dan Insentif dengan Kinerja Perawat Pelaksana di Rumah sakit Umum Daerah Pasaman Barat Tahun 2015. Tesis. Program Pascasarjana Universitas Andalas Padang. Padang 